\title{
Production Of Jute Yarns With Low Content OF UNSAPONIFIABLE MATTERS
}

\author{
F. A. Dilruba ${ }^{1}$, M. N. Amin ${ }^{1}$, M. E. Molla ${ }^{2}$, S. M. B. Rahman ${ }^{3}$ and Shamina Jafrin ${ }^{4}$ \\ ${ }^{1}$ Chemistry Division, Bangladesh Jute Research Institute, Dhaka 1207, Bangladesh \\ ${ }^{2}$ Chemistry Department, Jahangirnagar University, Savar, Bangladesh. ${ }^{3}$ Jahangirnagar \\ University, Savar, Bangladesh and ${ }^{4}$ Chemical Processing Department, Bangladesh Jute \\ Research Institute. \\ E-mail : drfdilruba70@gmail.com
}

\begin{abstract}
Castor oil having low content of unsaponifiable matters was chosen for the development of new jute batching emulsion processes. The suitability of the castor oil was also assessed in terms of its favourable colour, odour, specific gravity, acid value, iodine value, saponification value, viscosity, pour points and flash points in comparison to those of conventional JBO. Different recipes for the production of emulsions were standardized in the industrial scale and their suitability were assessed according to their stability, specific gravity, temperature, viscosity and pour points. The recipes were used to spin jute fibre in the jute mill machines. The yarn products were studied to evaluate their work performances based on their physico-chemical properties: moisture regain, t.p.i., W.I., count, strength, tenacity, extension, textile modulus, toughness, $Q R$, oil content and unsaponifiable matters. The yarn products were particularly evaluated in terms of their unsaponifiable matters based on the IJSG criterion. The yarns of processes show quality ratio 93.93 to 104.20 and unsaponifiable matters ranging from 126.05 to $414.92 \mathrm{mg} / \mathrm{kg}$ yarn and easily pass the IJSG criterion. The processes therefore appear to be of commercial importance.
\end{abstract}

Key words: Food items, IJSG criterion, JBO, Jute sacks, Unsaponifiables, Vegetable oils.

\section{Introduction}

Natural jute fibres, jute fibres pulled out from the pucca graded jute bales and the hard bottom .portion of long jute fibres (also known as jute cuttings) are stiff, brittle and less extensible owing to which the fibres show breakage and wastes during spinning [1]. To increase the softness, flexibility and improve the spinnability, jute fibres are conventionally softened before the carding stage of spinning operations by an emulsion of petroleum oil (bp. $270-450^{\circ} \mathrm{C}$ ) known as jute batching oil (JBO) along with a chemical emulsifier and water in different proportions ( ratio of emulsion ingredients $=$ oil : emulsifier : water $=20.0: 1.0: 79.0)$ for the production of fine yarns [2-7]. The jute sacks made of such yarns are used to transport various materials including foodstuffs such as peanuts, hazel nuts, shell nuts, cocoa beans, coffee beans, chocolate and confectionery products. The food stuffs are now reported to be contaminated by JBO hydrocarbons [810]. In fact, JBO hydrocarbons consist of nalkanes, isoalkanes (e.g. pristane, phytane) and aromatics. The n-alkanes are degradable by bacterial action and they do not exist in nature. They are not as such harmful. But the pristane, phytane, etc., resist bacterial action and accumulate in the nature in an undegradable state. Hence, they are harmful and are also not eco-friendly [10]. The Poly Aromatic Hydrocarbons fraction of the JBO containing compounds of $>3$ rings is recognized as chemical carcinogens and carries harmful effects. Furthermore, JBO emits kerosenic odour [11] and decreases the food value by this bad odour. In addition, the international Jute Study Group, IJSG (erstwhile IJO) after many international conferences, workshops and dialogues has imposed a criterion that the content of unsaponifiable matters in jute sack must not exceed the limit of $1250 \mathrm{mg} / \mathrm{kg}$ of the sack weight for transporting food stuffs, namely, cocoa beans, coffee beans and shell nuts [12]. Our laboratory test results indicate that JBO contains about $94.8 \%$ unsaponifiable matters [13]. The application of conventional JBO emulsion ( $20 \%$ on the weight of fibre, o.w.f) gives rise to $4 \%$ oil in the fibre and the application of $30 \%$ emulsion o.w.f gives rise to $6.0 \%$ oil in the fibre [2]. The calculation shows that these two treatments give rise to 
about 40,000 and 60,000 $\mathrm{mg}$ of unsaponifiable matter per kilogram of yarns. Such contents are indeed much greater than the allowable limit of the IJSG criterion. The necessity of new oil as substitute of JBO for batching jute fibre thus becomes inevitable to save the traditional market of jute sack from the impending danger.

Earlier some works [1,14] were carried for batching jute fibre by using castor oil and jute seed oil. The papers did not cover some important parameters such as flash point, viscosity, pour point and unsaponifiable matters of the new oils and emulsions in comparison to JBO and emulsion and their respective yarn products. The in-depth studies of these parameters are thus required to be investigated. So the present work was undertaken.

\section{Materials and Methods}

\subsection{Materials}

Bangladesh white jute fibres of pucca grade $\mathrm{C}$ (to be designated henceforth as BWC) were collected from the Amin Jute Exporters, Khanpur, Narayangonj. Castor oil (Commercial Grade, Made in Taiwan) was purchased from the local market. The JBO and the Nonidet P-40 (an emulsifying agent) were procured from the Padma Oil Company Ltd, Goadnyl, Narayangonj for the study.

\subsection{Methods}

2.2.1 Determination of the PhysicoChemical Properties of Castor Oil and JBO

The specific gravity, acid value and saponification value [15], iodine value [16], viscosity [17], flash point [18], pour point [19] and unsaponifiable matters of the JBO and those of the castor oil were determined by the standard methods $[13,20]$. The odour and colour were also determined by smelling and visually. The results are summarized (Table 1).

\subsubsection{Standardization of Emulsion Processes}

Based on the optimum laboratory process results, four different emulsion processes (i.e. C-1, C-2, C-3 \& C-4) were standardized in industrial emulsion tank (Rapisonic Emulsion Plant type JA, FR33 manufactured by Douglas Fraser and Sons Limited, United Kingdom) by using castor oil, nonidet P-40 (emulsifier) and water in different proportions. The emulsion ingredients and process parameters such as stability (S) in hours (h), specific gravity (D), temperature ${ }^{0} \mathrm{C}$ (T) of the processes (C-1 to C-4) are summarised (Table 2). The parameters of viscosity and pour points of the emulsion processes in comparison to JBO emulsion process are also presented (Figures I \& II).

2.2.3 The Application of Emulsions and Spinning of BWC into Yarns

BWC (100kg/batch) were batched with the respective emulsion (20kg/batch), piled (48h), and then subjected to mechanical processing machine (Jute Mills Machinery of the James Mackie \& Sons Ltd., Belfast, UK) for carding, drawing and spinning to convert into yarns.

\subsubsection{Determination of Moisture Regain and Bundle Strength}

The moisture regain [21] (\%MR) and Bundle Strength (mg/lb) of the BWC at the different stages of mechanical processing stages were determined. The results are presented (Table 3)

\subsubsection{Determination of Dust Content}

The loss of fibres as dust at the Breaker Card (B.C.) and Finisher Card (F.C.) were determined. The results are summarized (Table 4).

2.2.6 Determination of the PhysicoChemical Properties of the Yarns of Different Castor Oil and JBO Processes

The physical properties of the yarns relating to count, breaking load, breaking tenacity, extension, textile modulus, toughness and quality ratio were determined by Instron. Oil content and unsaponifiable matters were determined by standard method [20]. The moisture Regain [21] (\%), twist per inch (t.p.i.), and the whiteness index [22] of the yarns were determined by standard methods. The results are summarized in Table 5.

\section{Results and Discussion}

The work was undertaken to develop methods of batching of jute fibres using castor oil in order to replace the conventional JBO emulsion process which leads to produce yarns having harmful unsaponifiable matters. To assess the compatability of the castor oil with respect to JBO, some essential physicochemical properties of the castor oil were 
studied prior to development of methods for the preparation of emulsions. The standardised methods of different castor oil emulsions including their important properties were then studied.This followed the applications of the emulsions for spinning of BWC to produce yarns in the jute mill machinery. Lastly, the outcomes of the new processes and the JBO process were compared and evaluated in terms of their yarn properties. The results are discussed categorically as follows:

Table-1 shows some physico-chemical properties of JBO and castor oil. The lighter oil is usually preferable to heavier oil for making good emulsion by easy dispersion. It appears that the specific gravity of castor oil is slightly higher than that of JBO. However, it was presumed that this would not affect the preparation of emulsion, while low percentage of oil is used with the high proportion of water (90-97\%).It was found in later work that no difficulty was actually encountered during the preparation of emulsion. Similarly, no difficulty was presumed and actually experienced in making emulsion because of higher viscosity \& higher iodine value of the castor oil than those of JBO. The acid value of castor oil is slightly higher than JBO and is therefore deemed to be tolerable. The higher saponification value \& flash point, and lower pour point and unsaponifiable matter are desirable. In this sense, castor oil is better than JBO. Particularly, the unsaponifiable matter (\%) of the castor oil is very little in comparison to JBO and therefore safe for making emulsion for processing jute fibre for the production of yarns with low content of unsaponifiable matters. Furthermore, castor oil does not possess any bad odour and its colour is also appealing. So there is no hesitation to use the castor oil to make emulsion in order to replace the mineral oil (JBO) which possesses kerosenic odour and deep colour.

\section{Physico-chemical properties of JBO and castor oil}

Table 1 Physico-chemical properties of JBO and castor oil

\begin{tabular}{|l|c|c|}
\hline \multirow{2}{*}{ Parameters } & \multicolumn{2}{|c|}{ Oils } \\
\cline { 2 - 3 } & JBO & Castor Oil \\
\hline Specific gravity $(\mathrm{g} / \mathrm{cc})$ at $28^{0} \mathrm{C}$ & 0.87 & 0.95 \\
\hline Acid Value g KOH/100g oil & 3.49 & 1.73 \\
\hline Saponification Value mg KOH/100g oil & 14.38 & 179.01 \\
\hline Iodine Value g iodine/100g oil & 5.09 & 85.7 \\
\hline Viscosity (Redwood Seconds) & 48 & 298 \\
\hline Flash Point $\left({ }^{0} \mathrm{C}\right)$ & 125 & 15 \\
\hline Pour point $\left({ }^{0} \mathrm{~F}\right)$ & 32 & 1.03 \\
\hline Unsaponifiale Matters $(\%)$ & 94.80 & Not objectionable \\
\hline Odour & Kerosenic & Pale Yellow \\
\hline Colour & Reddish Brown & \\
\hline
\end{tabular}

\section{Emulsion ingredients and related parameters}

Table 2 Emulsion ingredients of the castor oil processes (C- 1 to C-4)

\begin{tabular}{|c|c|c|c|}
\hline Designation of process & Emulsion Ingredients (\%) & Emulsion Parameters & Remark \\
\hline C-1 & $\begin{array}{llc}\text { Castor oil } & : & 3.00 \\
\text { Nonidet } & : & 0.31 \\
\text { Water } & : & 96.69\end{array}$ & $\begin{array}{l}\mathrm{D}=0.996 \\
\mathrm{~T}=31^{0} \mathrm{C} \\
\mathrm{S}=168 \text { hour }\end{array}$ & $\begin{array}{l}\text { The emulsion was } \\
\text { homogeneous. No } \\
\text { frothing was observed. }\end{array}$ \\
\hline C-2 & $\begin{array}{llr}\text { Castor oil : } & 5.00 \\
\text { Nonidet } & : & 0.50 \\
\text { Water } & : & 94.50\end{array}$ & $\begin{array}{l}\mathrm{D}=0.994 \\
\mathrm{~T}=30^{0} \mathrm{C} \\
\mathrm{S}=96 \text { hour }\end{array}$ & $\begin{array}{l}\text { The emulsion was } \\
\text { homogeneous with } \\
\text { less stability in } \\
\text { comparison to C-1, C- } \\
3 \text { and C-4 process. No } \\
\text { Frothing was bserved. }\end{array}$ \\
\hline
\end{tabular}




\begin{tabular}{|c|l|l|l|}
\hline & $\begin{array}{l}\text { Castor oil : 7.00 } \\
\text { Nonidet }: 1.00 \\
\text { Water }: 92.00\end{array}$ & $\begin{array}{l}\mathrm{D}=0.993 \\
\mathrm{~T}=32^{0} \mathrm{C} \\
\mathrm{S}=144 \text { hour }\end{array}$ & $\begin{array}{l}\text { The emulsion was } \\
\text { homogeneous. Little } \\
\text { frothing was observed. } \\
\text { Stability is good. The } \\
\text { process appears ideal } \\
\text { and optimum. }\end{array}$ \\
& $\begin{array}{l}\text { Castor oil : } 10.00 \\
\text { Nonidet }: 1.50\end{array}$ & $\begin{array}{l}\mathrm{D}=0.992 \\
\mathrm{~T}=28^{0} \mathrm{C}\end{array}$ & $\begin{array}{l}\text { The process appears } \\
\text { inferior to C-3. Much } \\
\text { frothing was observed. } \\
\text { Cater }: 88.50\end{array}$ \\
& $\mathrm{~S}=168$ hour & Stability is good. \\
\hline
\end{tabular}

Table 2 shows the proportions of emulsion ingredients consisting of oil, emulsifier (nonidet) and water, and the emulsion parameters such as specific gravity (D), temperature (T), stability (S), and the visiual observations on the emulsions of different processes (C-1 to $\mathrm{C}-4)$. The processes require oil contents ranging from $3-10 \%$ with varying proportions of nonidet P-40 as emulsifier (0.31-1.50\%). It appears that all the processes (C-1 to C-4) are favourable to yield homogeneous oil in water emulsions of high stability (96-168 hour). The specific gravities of the emulsions appear to be lighter for smooth and fast penetration during piling process. The emulsion temperatures of the processes are also found within close range apprehending no significant affect during the processing of the fibres.

To assess the workability of the emulsions, the viscosity and the pour point of the concerned process were determined. The Fig. 1 shows that the viscosities of the new emulsions range from 26-29 (Redwood Seconds). It appears therein that the values are close to the viscosity of $20 \%$ JBO emulsion. Hence from the viscosity point of view, the new emulsions appear workable like that of $20 \% \mathrm{JBO}$ emulsion to process jute fibre.

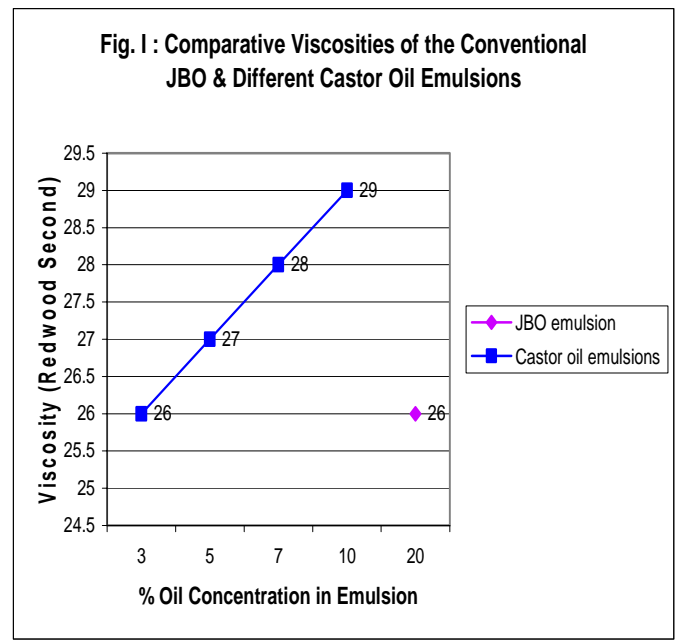

Fig. 1 Comparative viscosities of the conventional JBO $\&$ different castor oil emulsions

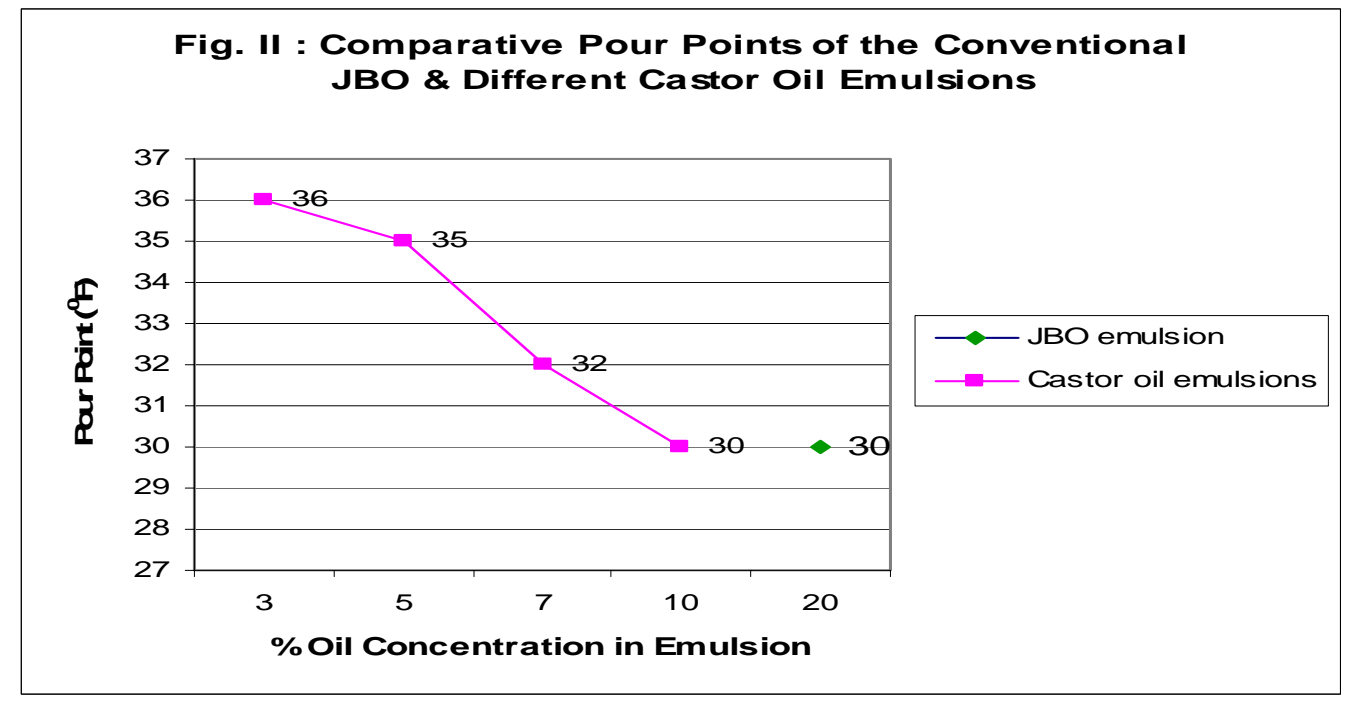

Fig. 2 Comparative pour points of the conventional JBO \& different castor oil emulsions 
Figure 2 shows the pour points (pour point is the lowest temperature in ${ }^{0} \mathrm{~F}$ or ${ }^{0} \mathrm{C}$ at which an emulsion remains pourable, meaning it to behave as a fluid) of the new emulsions along with $20 \%$ conventional JBO emulsion. The pour points are required to be considered to indicate their effective uses in tropical to more humid countries. It appears that the value of $10 \%$ castor oil emulsion (i.e. C-3 process) is identical with JBO process.
Furthermore, it shows that the pour points decrease with the increase of oil concentration in the emulsion. Accordingly, other emulsions with lower concentrations of oil appear to show slightly higher points than $10 \%$ castor oil \& $20 \%$ JBO emulsion. Hence all the emulsions (C-1 to C-4) are safe to be used for the desired batching of jute fibre like that of conventional JBO emulsion in similar environment of ambient temperature.

\section{MR and Bundle Strength of BWC during mechanical processing}

Table 3 MR and bundle strength of the BWC at the different stages of mechanical processing

\begin{tabular}{|c|c|c|c|}
\hline \multirow{2}{*}{$\begin{array}{c}\text { BWC treated with } \\
\text { Applied } \\
\text { Emulsion } \\
\text { Concentrations }\end{array}$} & \multirow{2}{*}{$\begin{array}{c}\text { BWC at } \\
\text { different stages of mechanical } \\
\text { processing }\end{array}$} & \multicolumn{2}{|c|}{$\begin{array}{l}\text { MR and Bundle } \\
\text { Strength }\end{array}$} \\
\hline & & $\begin{array}{l}\text { MR } \\
(\%)\end{array}$ & $\begin{array}{l}\text { Bundle } \\
\text { Strength } \\
\text { Lb/mg (CV\%) }\end{array}$ \\
\hline \multirow{8}{*}{$\begin{array}{l}\text { Treatment with } 20 \% \\
\text { JBO emulsion. }\end{array}$} & At the stage of control & 14.01 & $8.43(15.65)$ \\
\hline & $\begin{array}{l}\text { After adding emulsion and before } \\
\text { piling }\end{array}$ & 31.16 & $9.05(13.32)$ \\
\hline & After Piling (48 hour) & 34.23 & 9.01 (10.67) \\
\hline & After Breaker Card & 21.21 & 8.99 (16.79) \\
\hline & After Finisher Card & 15.80 & $8.58(13.05)$ \\
\hline & After First Drawing & 15.00 & $8.11(6.14)$ \\
\hline & After Second Drawing & 14.80 & $7.44(7.40)$ \\
\hline & After Third Drawing & 12.60 & $7.58(6.70)$ \\
\hline \multirow{8}{*}{$\begin{array}{l}\text { Treatment with 3\% } \\
\text { castor } \\
\text { oil emulsion } \\
\text { (C-1). }\end{array}$} & At the stage of control & 13.45 & $8.42(15.67)$ \\
\hline & $\begin{array}{l}\text { After adding emulsion and before } \\
\text { piling }\end{array}$ & 26.99 & $8.69(10.14)$ \\
\hline & After Piling (48 hour) & 28.19 & $7.52(8.14)$ \\
\hline & After Breaker Card & 26.27 & $7.28(7.88)$ \\
\hline & After Finisher Card & 23.47 & $7.01(9.25)$ \\
\hline & After First Drawing & 21.21 & $6.68(13.42)$ \\
\hline & After Second Drawing & 19.04 & $6.36(3.00)$ \\
\hline & After Third Drawing & 14.95 & $6.21(7.47)$ \\
\hline \multirow{8}{*}{$\begin{array}{l}\text { Treatment with 5\% } \\
\text { castor } \\
\text { oil emulsion } \\
\text { (C-2). }\end{array}$} & At the stage of control & 13.50 & $8.48(15.63)$ \\
\hline & $\begin{array}{l}\text { After adding emulsion and before } \\
\text { piling }\end{array}$ & 27.79 & $8.61(9.15)$ \\
\hline & After Piling (48 hour) & 29.03 & $7.47(7.27)$ \\
\hline & After Breaker Card & 26.58 & $7.25(12.09)$ \\
\hline & After Finisher Card & 25.00 & $6.44(12.03)$ \\
\hline & After First Drawing & 22.69 & $7.10(9.69)$ \\
\hline & After Second Drawing & 21.21 & $7.18(10.54)$ \\
\hline & After Third Drawing & 18.11 & $6.52(10.76)$ \\
\hline \multirow{7}{*}{$\begin{array}{l}\text { Treatment with } 7 \% \\
\text { castor } \\
\text { oil emulsion } \\
\text { (C-3). }\end{array}$} & At the stage of control & 14.34 & $8.39(15.58)$ \\
\hline & $\begin{array}{l}\text { After adding emulsion and before } \\
\text { piling }\end{array}$ & 32.48 & $8.46(10.34)$ \\
\hline & After Piling (48 hour) & 34.23 & 7.98(8.37) \\
\hline & After Breaker Card & 33.00 & $7.48(11.57)$ \\
\hline & After Finisher Card & 31.57 & $6.91(6.25)$ \\
\hline & After First Drawing & 28.20 & $7.64(10.71)$ \\
\hline & After Second Drawing & 24.48 & $6.94(9.88)$ \\
\hline
\end{tabular}




\begin{tabular}{|c|c|c|c|}
\hline \multirow{3}{*}{$\begin{array}{l}\text { BWC treated with } \\
\text { Applied } \\
\text { Emulsion } \\
\text { Concentrations }\end{array}$} & \multirow{2}{*}{$\begin{array}{c}\text { BWC at } \\
\text { different stages of mechanical } \\
\text { processing }\end{array}$} & \multicolumn{2}{|c|}{$\begin{array}{l}\text { MR and Bundle } \\
\text { Strength }\end{array}$} \\
\hline & & $\begin{array}{l}\text { MR } \\
(\%)\end{array}$ & $\begin{array}{l}\text { Bundle } \\
\text { Strength } \\
\text { Lb/mg (CV\%) }\end{array}$ \\
\hline & After Third Drawing & 18.57 & $6.91(9.34)$ \\
\hline \multirow{8}{*}{$\begin{array}{l}\text { Treatment with } 10 \% \\
\text { castor oil emulsion } \\
\text { (C-4). }\end{array}$} & At the stage of control & 13.05 & $8.40(15.60)$ \\
\hline & $\begin{array}{l}\text { After adding emulsion and before } \\
\text { piling }\end{array}$ & 36.98 & $8.52(12.14)$ \\
\hline & After Piling (48 hour) & 39.38 & 7.71(9.59) \\
\hline & After Breaker Card & 33.30 & $6.92(9.47)$ \\
\hline & After Finisher Card & 31.68 & $7.23(8.00)$ \\
\hline & After First Drawing & 28.28 & $6.03(3.37)$ \\
\hline & After Second Drawing & 28.20 & $6.56(8.41)$ \\
\hline & After Third Drawing & 23.97 & $6.88(12.65)$ \\
\hline
\end{tabular}

The parenthesis indicates the percentage coefficient of variations (CV\%).

Table 3 shows the moisture regain (\%MR) and bundle strength of BWC fibres at different stages of mechanical processing. The fiber must remain sufficiently wet during spinning operations to facilitate smooth spinning with minimum fibre breakage, fibre waste and retaining tolerable bundle strength. It appears that the BWC maintained good retention of moisture in all stages of operations (carding to drawing) facilitating good spinnability as compared to JBO process, and the processes therefore appear favourable. The castor oil processes show a little lower bundle strength than the JBO process. The bundle strength of the fibre at the third drawing stages were $8.42,8.48$, 6.52, 6.91 and $6.88 \mathrm{lb} / \mathrm{mg}$ in JBO, C- $1, \mathrm{C}-2$, C-3 \& C-4 processes respectively. Among the new processes (C-1 to C-4), it appears that the bundle strength decreases with the increase of oil concentration.

\section{Fibre wastes during mechanical processing of BWC}

Table 4 Dust contents at the B.C. and F.C. during mechanical processing of BWC

\begin{tabular}{|c|c|c|c|}
\hline \multirow{2}{*}{ Process } & \multicolumn{3}{|c|}{ Dust Content (\%) } \\
\cline { 2 - 4 } & Breaker Card (B.C.) & Finisher Card (F.C.) & Total (B.C. + F. C.) \\
\hline JBO (20\%) & 1.20 & 0.60 & 1.80 \\
\hline C-1 (3\%) & 1.75 & 0.63 & 2.38 \\
\hline C-2 (5\%) & 1.50 & 0.44 & 1.94 \\
\hline C-3 (7\%) & 2.00 & 0.53 & 2.53 \\
\hline C-4 (10\%) & 1.64 & 0.53 & 2.17 \\
\hline
\end{tabular}

In Table 4, the loss of fibre in terms of dust contents of the fibre at the breaker card and finisher card during mechanical processing for the different processes (JBO \& C-1 to C4) are presented. The JBO process shows a little lower dust content than the castor oil processes, but the difference is minor in nature. The processes therefore appear to be modest and comparable to JBO process

\section{Evaluation of the physico-chemical properties of the yarns}

Table 5 Physico-chemical properties of the yarns of different castor oil processes (C-1 to C-4) and JBO processes

\begin{tabular}{|l|c|c|c|c|c|}
\hline \multirow{2}{*}{ Properties } & \multicolumn{5}{|c|}{ Yarns of JBO and Castor Oil Emulsion Processes (C-1 to C-4) } \\
\cline { 2 - 6 } & $\begin{array}{c}\text { JBO } \\
\text { (20\%) }\end{array}$ & $\begin{array}{c}\text { C-1 } \\
\text { (3\%) }\end{array}$ & $\begin{array}{c}\text { C-2 } \\
\mathbf{( 5 \% )}\end{array}$ & $\begin{array}{c}\text { C-3 } \\
\mathbf{( 7 \% )}\end{array}$ & $\begin{array}{c}\text { C-4 } \\
(10 \%)\end{array}$ \\
\hline MR (\%) & 11.70 & 11.11 & 11.11 & 13.30 & 9.30 \\
\hline t.p.i. (Nos.) & 4.02 & 3.82 & 3.84 & 3.88 & 3.82 \\
\hline
\end{tabular}




\begin{tabular}{|l|c|c|c|c|c|}
\hline W.I. (\%) & 31.52 & 32.28 & 33.47 & 34.47 & 35.58 \\
CV\% & 3.08 & 4.28 & 5.73 & 3.98 & 2.03 \\
\hline Count(lb/spy & 7.64 & 8.078 & 7.585 & 8.011 & 8.112 \\
(Tex) & $(263.2)$ & $(278.3)$ & $(261.3)$ & $(275.6)$ & $(279.5)$ \\
CV\% & 5.64 & 2.988 & 7.676 & 3.596 & 8.653 \\
& & & & & \\
\hline Maximum Breaking Load * (Kgf) & 4.227 & 3.564 & 3.584 & 3.667 & 3.456 \\
CV\% & 15.58 & 17.07 & 17.29 & 16.69 & 20.99 \\
\hline Brk. Tenacity (cN/tex) & 15.76 & 12.58 & 13.47 & 13.03 & 12.13 \\
CV\% & 15.58 & 17.07 & 17.29 & 16.69 & 20.99 \\
\hline Extension At Break (\%) & 1.972 & 1.752 & 1.885 & 2.098 & 1.95 \\
CV\% & 11.55 & 12.13 & 13.15 & 15.08 & 15.69 \\
\hline Textile Modulus (N/Tex) & 10.93 & 9.055 & 9.188 & 8.348 & 8.257 \\
CV\% & 7.58 & 10.69 & 10.00 & 9.23 & 14.04 \\
\hline Toughness (mN/tex) & 1.298 & 0.9641 & 1.1070 & 1.171 & 1.003 \\
CV\% & 25.44 & 25.96 & 27.77 & 29.61 & 32.45 \\
\hline QR (\%) & 122.00 & 97.27 & 104.20 & 100.90 & 93.93 \\
CV\% & 15.58 & 17.07 & 17.29 & 16.67 & 20.99 \\
\hline Oil content (\%) & 4.3 & 1.28 & 2.24 & 3.41 & 4.19 \\
\hline Unsaponifiable Matters (mg/kg yarn) & 39,640 & 126.05 & 218.08 & 333.34 & 414.92 \\
\hline
\end{tabular}

* Maximum Breaking Load is for single yarn.

Table 5 shows the basic yarn properties of the processes to indicate their work performances in comparison to JBO process. These are highlighted as follows:

\section{Physical properties of the yarns \\ Moisture Regain (\%MR)}

The yarns of the castor oil processes mostly show lesser \%MR than that of the JBO yarns. The C-3 process shows a little higher \%MR value. It may be considered minor in nature. So it may be remarked that all the processes have produced more or less comparable moisture in yarns in comparison to JBO yarns.

\section{Twist per inch (t.p.i.)}

The t.p.i. values of the yarns of the processes are a bit lower than the JBO process yarns. The reason of variations of parameter is attributed to arise due to retaining higher content of moisture in the fibre during the mechanical processing of BWC already cited (Table 3).

\section{Whiteness Index (\%W.I.):}

It appears that the castor oil processes yield yarns of greater whiteness than JBO process. The whiteness index increases with the increase of castor oil concentration. The $\mathrm{CV} \%$ of the determinations of W.I. appears to be quite satisfactory. The castor oil shows some whitening effect. The value increases with the increase of oil concentration.

\section{Count:}

The count values of the yarns are expressed both in terms of (lb/spy) and (Tex). The reason of variations of parameter is due to lesser twist during spinning for higher percentage of moisture in the fibre at the different processing sequences (Table 3).

\section{Maximum breaking load}

It appears that the test yarns (C-1 to $\mathrm{C}-4)$ exhibit lesser strength, which resulted due to lesser twist insertion during spinning sequences. The reasons for this have been discussed already in the foregoing discussion. However, the C-3 process approaches JBO process in this respect. The $\mathrm{CV} \%$ of $\mathrm{C}-3$ was found to be 16.69 , while that of JBO process was 15.58. So the C-3 process appears comparable to JBO process.

\section{Breaking tenacity}

The breaking tenacity (which is a measure of tensile stress/force expressed in terms of gram/tex) of the C-1 to C-4 processes appears to be lesser than that of the JBO process, which resulted due to lesser twist during spinning as already referred to above. However, the values of C-2 \& C-3 processes are nearer to JBO process.

\section{Extension (\%)}

The extensibility of the yarns was studied. The percent elongation was calculated during tensile test of the yarns at break by measuring the increase in length of the yarns. The data of the extensionability of the test yarns are comparable to JBO data. The C-3 process is 
found to produce more extensible yarn than all other processes of the study and its $\mathrm{CV} \%$ are also tolerable in comparison to JBO process. So C-3 process appears favourable.

\section{Textile Modulus}

The textile modulus is an important property to indicate the degree of extensibility of a yarn, which is determined by the ratio of stress and strain of the yarn. It is worthwhile to mention that high modulus indicates inextensibility (i.e. rigidity) and low modulus indicates great extensibility (i.e. elongation behaviour). In view of this, the textile modulus of the yarns was determined and compared. It appears from the data that the test yarns are less rigid than JBO yarns. The $\mathrm{CV} \%$ of the results are found to be within acceptable limit. Particularly, the CV\% of $\mathrm{JBO}$ and $\mathrm{C}-3$ processes are closer.

\section{Toughness}

It is essential to know about the toughness of yarns. Toughness represents a property of a yarn by virtue of which it can absorb work. The work of rupture is a measure of toughness. For this purpose, the toughness of the yarns was determined and compared. It appears that the toughness of the JBO yarns is slightly higher than those of test yarns. The data conform to the other textile parameters such as breaking load, tenacity, extensibility and modulus of the yarns as cited in the foregoing discussion. The $\mathrm{CV} \%$ was found a bit higher.

\section{Quality ratio}

The quality ratio $(\mathrm{QR})$ is the foremost important parameter required to evaluate the process performance of a yarn, which is the ratio of its breaking load in pounds divided by the value of grist in lb per spindle $(14,000$ yds) multiplied by 100 . So the QR of the yarn were determined and compared including their $\mathrm{CV} \%$. The $\mathrm{C}-2$ and the $\mathrm{C}-3$ processes show QR\% of 104.2 and $100.90 \%$ respectively. So considering all other properties the $\mathrm{C}-2$ and $\mathrm{C}-3$ with oil concentrations of $5 \%$ and $7 \%$ appear to be modest and economical for industrial use.

\section{Chemical properties}

\section{Added oil content (\%) of yarns}

Generally, low contents of oil makes the yarn harsh feel, non-smooth and projects more hair. This also decreases the appealing properties of the yarn. So a tolerable level of oil content in the yarn is desirable. In view of this, the oil contents of the yarns of different processes were determined and compared. The JBO yarns show oil content of $4.3 \%$, which the users used to accept for quite a long time. In this context, the oil contents of C-1, C-2, C-3 \& C-4 processes were assessed and compared with JBO yarns (Fig 3).

Fig. III : Comparative Added Oil Content (\%) of Yarns of the JBO \& Castor Oil Processes

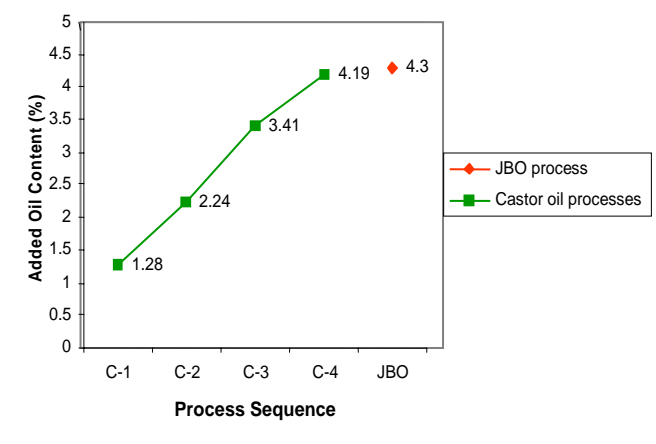

Fig. 3 Comparative added oil content (\%) of yarns of the JBO \& castor oil processes

It appears that C-3 \& C-4 processes show oil contents relatively close to the JBO process. So these two processes appear favourable. Normally, yarns having at least $2 \%$ oil content are desirable. So the $\mathrm{C}-1$ process is not acceptable. The oil content of $\mathrm{C}-2$ process is just marginally acceptable (Fig. III). However, C-2 to C-4 processes appears good to be used.

\section{Unsaponifiable Matter}

It may be recalled that in section I (in introduction) it was mentioned that jute yarns to be used for making sacks having unsaponifiable matters exceeding $1250 \mathrm{mg} / \mathrm{kg}$ of yarn weight are not acceptable for the sacks to be used for food items. So the contents of unsaponifiable matters in C- 1 to C-4 \& JBO yarns were determined. The results were compared based on this cited criterion $^{12}$. It appears that the yarns of $\mathrm{C}-1$, $\mathrm{C}-2, \quad \mathrm{C}-3 \quad \& \quad \mathrm{C}-4$ processes contain unsaponifiable matters: 126.05, 218.08, 333.34 , \& $414.92 \mathrm{mg} / \mathrm{kg}$ yarns respectively, which are all far below the allowable limit of IJSG criterion and are safe to pass the criterion. The castor oil processes, therefore, appear viable to be used in place of conventional JBO process for the production of jute yarns with low content of unsaponifiable matters to make jute sacks for transporting food items safely. 


\section{Conclusions}

From the foregoing discussion it is clear that a significant achievement has been obtained to overcome present burning problem of jute industry. The JBO contains kerosenic odour and a high level of unsaponifiable matters and as such it cannot continue further for batching of jute fibres in order to produce jute sacks for foodstuffs. As a matter of fact, alternative batching method with an oil of low content of unsaponifiable matter and good odour is essential.

The readily available and annually renewable castor oil contains very little unsaponifiable matters (1.03\%) having a good odour. The standardized process involving castor oil-7\%, nonidet (P-40)-1.0\% and water-90\% shows around 144 hours stability at ambient temperature indicating smooth and safe use in jute industry. The process, therefore, appear to be modest and demonstrable in jute industry.

\section{References}

[1] Amin M N \& Begum M, J Text Inst, 87(1), 3 (1996) 432.

[2] Kundu B C, Jute in India, (Indian Central Jute Committee, Kolkata, India), 1958.

[3] Chatterjee K K, Saha P K \& Sarkar P B, Text Mfr, 87 (1961) 425.

[4] Chatterjee K K \& Saha P K, Agric Residues, 3 (1963) 40.

[5] Chatterjee K K \& Saha P K, Text Mfr, 92 (1966) 186.

[6] Atkinson R R, Jute Fibre to Yarn, (Chemical Furnishing Company, New York, NY, USA), 1965.
[7] Technical Bulletin, Batching Emulsion and Condtioning, James Mackie and Sons Ltd. Belfast, Northern Ireland.

[8] Konrad Grob, Mauro Landfranchi, Jnes Egli \& Anna, Artho, kantonal labor, P. O. Box, CH-8030, Zurich, Switzerland, (1990).

[9] US Food and Drug Administration Regulation No. 1783620.

[10] Rahman M T, Biswas P K, Nur H P \& Mahmood A J, Report on investigation on the possible contamination of food items from jute fibres produced with jute batching oil, (Bangladesh Jute mills corporation, Dhaka), 1992.

[11] Agarwal Rajesh, Sushil Kumar \& Mehrotra N K, Journal of Chromatography Science, 24 (7), (1986) 289.

[12] Special criteria for the manufacture of jute bags used in the packaging of selected food materials (cocoa beans, coffee beans and shell nuts), (International Jute Organization, IJO, Standard/98/02 )1998.

[13] Dilruba F A, Studies on the Suitable Vegetable Oils for Manufacturing of Jute Sack with Low Level of Unsaponifiable Matters, Ph.D. thesis, Jahangirnagar University, Savar, Bangladesh, 2007.

[14] Amin M N, Dilruba F A, Kabir, M K, Lutfar Latifa Binte, Mahbubuzzaman A K M \& Ahmed Farid, Journal of Bangladesh Academy of Science, Vol 25, No. 2, (2001) 131.

[15] Pearson D, The Chemical Analysis of Food, (J \& A Churchill, London, $6^{\text {th }}$ edition), 1970.

[16] Hanus J, Untersuch Lebenson, 4, (1901), 913.

[17] ASTM-D445-IP, The Redwood No.I Viscometer.

[18] ASTM-D92, Flash Point Pensky Martens Apparatus

[19] ASTM-D97-96a Standard test method for pour point of petroleum products (IP 15/95)

[20] British Standard : 3845,1990.

[21] Reddy S S \& Bhaduri S K, Journal of Applied Polymer Science, Vol. 39, (1990) 553.

[22] Roy T K Guha, Chatterjee S, Adhikari D \& Mukherjee A K, Journal of Textile Institute, 79, (1988) 108. 